Doi: https://doi.org/10.31578/jebs.v6i2.241

\title{
Family Socio-Economic Status, School Location and Students' Eco-Friendly Knowledge, Attitude and Practices in Nigeria
}

\author{
Ramoni Afolabi Olubela*
}

\begin{abstract}
The school system, regardless of the level of operation, is generally accepted as a major agent of education. It provides avenues for interaction between students and teachers on subject matters. However, the location of the school determines many students' knowledge, attitude and practices. Also, there is an increasing awareness of the importance of the parents' role in the progress and educational development of their children. Family background as an important and weighty factor in determining the academic performance attained by the student needs to be investigated. This study adopted a pre-test-post-test control group quasi-experimental design. Intact class of Junior Secondary School II Social Studies students in each of the six schools in Oyo state were randomly assigned to the experimental and control groups. Three validated instruments were used in this study, and they are Environmental Education Knowledge Test (EEKT), Environmental Education Attitude Scale (EEAS) and Environmental Education Practice Questionnaire (EEPQ). The data were analyzed using Analysis of Covariance (ANCOVA) with the pretest scores used as covariates. All the null hypotheses were tested at $P<.05$ level of significance. The study showed a significant two-way interaction effect of family socio-economic status and school location on students' eco-friendly knowledge, attitude and practices. It was recommended that schools should be kept safe and parents should develop more streams of income, as a single income source has become a great economic challenge in Nigeria.
\end{abstract}

Key words: family socio-economic status, school location, students' eco-friendly knowledge, students' eco-friendly attitude, students' eco-friendly practices, school security, alternative income

\section{Introduction}

A number of variables actually affect the students' knowledge of and attitude to environmental issues and problems. These variables include students' academic ability, personality traits, home influences, school influences, religious beliefs, school type, location and cultural practices, among others. For this study, the moderating effects of family socio-economic status (low, medium and high) and school location (urban and rural) on students' environmental knowledge, attitude and practice will be examined.

The responsibility of training a child always starts at home with the parents. In this wise, family socio-economic background can have possible effects on overall development of the children. Parental income has been found to influence children's knowledge, attitude and values. Oni (2007) and Omoegun (2007) averred that there is a significant difference between the rates of deviant behaviour among students from high and low family income. Also, Gbadamosi (2012) observed that when a child gets proper nutrition, health care, proper sewage and refuse disposal experience, and the ability to interact well with the

\footnotetext{
* Dr. Department of Arts \& Social Sciences Education, Olabisi Onabanjo University, Ago-Iwoye, Ogun State, NIGERIA

Corresponding Email: afolabi.olubela@oouagoiwoye.edu.ng
} 
environment, such child would not be found wanton in many spheres of life (Ugboma, 2002). In view of the general poverty level in Nigeria, the intention of this study is to determine whether there would be any significant difference in the environmental learning outcomes among students from high, medium and low parental income.

The value, which each family attaches to school education, determines the motivation with which its children pursue education. In high socio-economic status homes, children are encouraged to wake up early and prepare for school. Children from low socio-economic status homes where other activities in the home are valued more than schooling always go late to school. Constant late coming to school is bound to have an adverse effect on academic performance.

Also, school location has generated a lot of interest in educational research. Balogun (2012) asserts that one's residential/school location influences his/her perception generally. He noted that people in urban areas are typically exposed to a wider range of experiences than people in rural areas. To Ezewu (2009), those living in the urban centres or cities have wider access to sanitary facilities, and the level of their compliance with environmental laws and regulations are higher than those in the rural centres. Olatundun (2008) in his own reiterates that poverty, sterile environment and low standards of social services characterize rural environment to the extent that the residents' perception is jaundiced. In a similar vein, Ezewu (2012) asserted that some features of the rural environment impact on the residents negatively, so much that they influence their perception and consequently their attitude and practices. This study therefore seeks to determine whether a significant difference will be observed in the environmental knowledge, attitude and practice of students in the urban and rural areas.

The socio-economic status of a child's family is significantly related to his level of educational aspiration and to school performance. In high socio-economic status families, in order to maintain their status, do everything possible to ensure that their children attend the best nursery and primary schools which guaranteed admission to highly placed secondary schools, the entrance to which is usually competitive. These highly placed secondary schools provide the best route to university education, thus guaranteeing access to higher education and consequently access to a prestigious occupation and high income for their children. Children from relatively high socio-economic status have traditionally aspired to higher educational levels than their lower class peers. Parents and children from higher socio-economic status tend to view education as having intrinsic value quite apart from its functions of increasing vocational opportunities and economic rewards. Studies have suggested that higher-class parents place greater emphasis on the maintenance of high levels of schools and vocational success than lower economic parents do.

Hence, these three hypotheses were to be analysed at 0.05 level of significance:

Ho1: There is no significant interaction effect of parental income and school location on students' knowledge of environmental education concepts.

Ho2: There is no significant interaction effect of parental income and school location on students' attitude to environmental education.

Ho3: There is no significant interaction effect of parental income and school location on students' environmental practices.

\section{Literature review}

There are many factors that influence children's academic success. Some of these factors are the parent's education level and socioeconomic factors. It is suggested that family environments were much more important than school environments in influencing adolescent's aspirations (Olatundun, 2008). In a longitudinal study of the National Centre for Educational Statistics 
(2009), a study on parental educational aspirations and environment factors was conducted to determine the effect on children Parent's education Level was put into two different categories. One category was less than a bachelor's degree and the other was bachelor's degree to Ph.D. or other advanced professional degree. The effects on adolescent's educational aspirations were found for parents' educational level, perceived father's and mother's aspiration for adolescent, and parents' influence on high school plans. The findings included that parents who had a high level of education tended to have higher aspirations for their children than less educated parents.

This study is anchored on the Social Cognitive Theory which started as the Social Learning Theory (SLT) in the 1960s by Albert Bandura (2001). The theory developed into the Social Cognitive Theory (SCT) in 1986. Bandura advanced a view of human functioning that accords a central role to cognitive, vicarious, self-regulatory and self-reflective processes in human adaptation and change. The theory is based on the assumption that people are purposeful, goal-directed beings who are primarily motivated through their beliefs of self-efficacy and outcome expectations stemming from their actions within specific social contexts. The Social Cognitive Theory explains human agency through the interdependence of determinants using a three-point model called "triadic reciprocal causation". The model visually resembles a triangle with the following points interacting and mutually influencing each other: personal factors $(P)$ (which include cognitive, affective, and biological events), environment (E), and behaviour (B).

The Social Cognitive Theory is rooted in a view of human agency in which individuals are agents proactively engaged in their own development who can make things happen by their actions. Key to this sense of agency is the fact that, among other personal factors, individuals possess self-beliefs that enable them to exercise a measure of control over their thoughts, feelings, and actions, what people think, believe, and feel affects how they behave. Bandura (2001) provided a view of human behavior in which the beliefs that people have about themselves are critical elements in the exercise of control and personal agency. Thus, individuals are viewed both as products and as producers of their own environments and of their social systems. Since human lives are not lived in isolation, Bandura expanded the conception of human agency to include collective agency. People work together on shared beliefs about their capabilities and common aspirations to better their lives. This conceptual extension makes the theory applicable to human adaptation and change in collectivistic ally-oriented societies as well as individualistically-oriented ones (Bussey \& Bandura, 1999).

Environments and social systems influence human behaviour through psychological mechanisms of the self-system. Hence, the Social Cognitive Theory posits that factors such as economic conditions, Socio Economic Status (SES), educational and family structures do not affect human behaviour directly. Instead, they affect it to the degree that they influence people's aspirations, self-efficacy beliefs, personal standards, emotional status, and other self-regulatory influences. In all, this socialcognitive view of human and collective functioning, which marked a departure from the prevalent behaviourist and learning theories on focus, was to have a profound influence on psychological thinking and theorizing during the last two decades of the twentieth century and into the new millennium.

In another study, parental educational attainment has been found to be significantly related to the educational attainment of their children in both rural and national samples (Balogun, 2012). That study also had two levels of judging education levels. The two levels are some college or below to college graduate and above. As with the case previously, the children of the more educated group tended to have higher aspirations and had higher education plans.

A research using binominal logistic regression techniques indicate that gender, unexplained absences, parental educational attainment, housing type, ethnicity and student age are all statistically significant variables and predicators of academic performance. In contrast, family structure, the main source of family income and geographical location, does not 
significantly predict outcomes in school performance once other factors are controlled. The findings support the notion that the "social" and the economic components of the socio- economic status equation have distinct and separate influences on educational outcomes. While financial assistance to schools and families in need is important, policies and programmes that also assist low-income parents in providing appropriate psychological and educational support for their children should also be promoted (Balogun, 2012).

For most children, failure to thrive describes the endpoint of a process that involves medical and nutritional as well as psychological and social influences. There is evidence of an association between malnutrition and stressors in the family environment and in parent-child interaction, although some researchers have urged a careful review of this evidence. In general, the various studies studies such as Omoegun (2007), Olatundun (2008) and Ajiboye (2010) which attempt to explain academic failure do so beginning with the three elements that intervene in education: parents (family causal factors), teachers (academic causal factors), and students (personal causal factors). Among the personal variables most studied are motivation and selfconcept. Motivation is considered to be the element that initiates the subject's own involvement in learning: when a student is strongly motivated, all his/her effort and personality are directed toward the performance of a specific goal, this bringing to bear all his or her resources.

According to Oginni (2008), a consensus exists among the diverse motivational theories and approaches in as much as they conceptualize motivation in terms of conscious beliefs and values. In the arena of motivation there exist all kinds of opinions and results; some research claims that motivation maintains a circular relationship with the level of information processing and this, in turn, with performance. In another research, motivation was found to be one of the elements that most distinguishes those required to repeat a school year from those being promoted, the repeaters being those who are most bored in the class. Other authors have found that subjects themselves attribute low performance to low ability and to luck, and an improvement in performance - to motivation (task goal orientation), self-regulating behaviours, and to competence as a function of task characteristics (Oni, 2007).

Gbadamosi (2012) showed positive correlations between the value given to the task and the perceptions of auto-efficacy and performance. Academic self-concept is at the base of future school success or failure, having been formed starting in early childhood education from peer contact and teacher attitude and expectations. To Balogun (2012), positive self-concept is one risk-reducing factor against academic failure in the case of unfavourable family situations.

Adebule and Aborisade (2013) emphasized that parents whose educational levels are secondary education or above were mostly in better-payed jobs, professional men (doctors, lawyers, lecturers, civil servants and so on). Whereas parents who have only primary education or are illiterate were petty traders, labourers, bricklayers, etc. most of who have very low incoms. The level of education attained determines the type of job the parents do and hence their socio-economic background. The reasons are: children from high socio-economic background have access to reading materials at home, which hasten their reading materials at home and their reading readiness, they often attend special fee-paying schools which are generally better than the free primary schools. According to Gbadamosi (2012), such parents attend extra lessons after the school hours, hence they perform better in intelligence and performance tests than children from low socio-economic homes who are faced by circumstances to saddle the young ones with chores like hawking wares, cleaning the house, leaving little or no homes of parents with high socio-economic status background, toys, gadgets which the children manipulate are found, many skills are developed by the children while interacting with these materials. All these again confirms the fact that home environment has a significant effect on students' academic attainment. The higher the socio-economic status of a child's family, the higher his or her academic performance. 
Another aspect of parental motivation which Ezewu (2012) investigated was parental reaction to poor performance at school. It was found that high socio-economic status families tend to show much concern over their children's poor performance at school. Most of them either teach their children those subjects in which the children perform very poorly or they hire part-time teachers for them. Even if low socio-economic status families are worried over thyeir children's poor performance, they are not always able to coach, their children well because the parents themselves have had little or no education, so they may not be able to help their children and may not be able to afford to hire a part-time teacher because of their poor income.

On school location, either rural or urban, Fontana (2011) asserted that school location generally influences students' perception. He noted that people in urban areas typically are exposed to a wider range of experiences. The print and electronic media, information technology and fairly stocked libraries are available to them to boost their experience. Also, modern sanitary facilities such as water closets, incinerators, waste disposal trucks, sanitary officers, etc. are common in the urban areas. Therefore, schools in the urban areas have the advantage of these facilities over students in rural school setting. Consequent upon this experience students in the urban centres are more likely to perceive the realities of environmental management better than their counterparts in rural areas. Heckman (2008), on his part, observed that poverty, sterile environment and low standards of social services characterize rural environment to the extent that the residents' perception is jaundiced. Thus, the rural dwellers hardly see anything wrong with indiscriminate refusal and sewage disposals. The reverse is rather the case with those who leave in urban areas. In a similar vein, Ezewu (2009) concluded that some features of the rural environment impact on the students negatively, so much so that they influence their perception and consequently their environmental knowledge, attitude and eco-friendly practices.

\section{Methodology}

\subsection{Methods:}

This study adopted a pre-test-post-test control group quasi-experimental design.

\subsection{Background information:}

Oyo State was selected because it is a community of urban and rural locations. Also, many families in this region range from high, medium to low socio-economic status. In addition to these demographic parameters, Oyo state is currently witnessing many environmental challenges resulting from human activities, in the selected local government areas and posing some hazards to equitable and sustainable environment.

\subsection{Participants:}

The participants in this study consisted of junior secondary school II students in six schools from four local government areas of Oyo state. The six schools and four local government areas were purposively selected. Intact class of junior secondary school II Social Studies students in each of the six schools were randomly assigned to the experimental and control groups.

\subsection{Procedure:}

Three validated instruments were used in this study, and they are Environmental Education Knowledge Test (EEKT), Environmental Education Attitude Scale (EEAS) and Environmental Education Practice Questionnaire (EEPQ. The data were analyzed using Analysis of Covariance (ANCOVA) with the pretest scores used as covariates. The Estimated Marginal Mean (EMM) was used to determine the magnitude of the mean scores of the different groups. The Scheffé Post-hoc was used to determine the sources of such 
significant differences, and graphs were used to interpret significant interaction effects. All the null hypotheses were tested at $\mathrm{P}$

$<.05$ level of significance.

\subsection{Results and analysis}

Ho1: There is no significant interaction effect of parental income and school location on students' knowledge of environmental education concepts

Table 1: Analysis of Covariance (ANCOVA) of Post-knowledge scores by parental income and school location

\begin{tabular}{|l|l|l|l|l|l|l|}
\hline Source & $\begin{array}{l}\text { Type III Sum of } \\
\text { Squares }\end{array}$ & Df & Mean Square & F & Sig. & $\begin{array}{l}\text { Partial Eta } \\
\text { Squared }\end{array}$ \\
\hline Corrected Model & $2017.831^{\mathrm{a}}$ & 18 & 112.102 & 25.719 & .000 & .558 \\
Intercept & 10111.910 & 1 & 10111.910 & 2319.895 & .000 & .863 \\
Pre-knowledge & 1.013 & 1 & 1.013 & .232 & .630 & .001 \\
Parental Income & 4.648 & 2 & 2.324 & .533 & .587 & .003 \\
School location & 4.801 & 1 & 4.801 & 1.101 & .003 \\
Parental Income * School \\
location
\end{tabular}

a. $\mathrm{R}$ Squared $=.558(\text { Adjusted } \mathrm{R} \text { Squared }=.536)^{*} \quad=$ Significant at $\mathrm{P}<0.05$

The students' knowledge of environmental education concepts in Table 1 revealed that the interaction effect of family socioeconomic status and school location on students' knowledge of environmental education concepts is not significant $\left(F_{(2,367)}=\right.$ $1.514, \mathrm{P}>05, \mathrm{\eta} 2=0.008)$. Therefore, the null hypothesis Ho1 was not rejected.

Ho2: There is no significant interaction effect of parental income and school location on students' attitude to environmental education

Table 2: Analysis of Covariance (ANCOVA) of post-attitude by parental income and school location

\begin{tabular}{|l|l|l|l|l|l|l|}
\hline Source & Type III Sum of Squares & $\mathbf{d f}$ & Mean Square & $\mathbf{F}$ & Sig. & $\begin{array}{l}\text { Partial Squared } \\
\text { Sta }\end{array}$ \\
\hline Corrected Model & $3716.652^{\mathrm{a}}$ & 18 & 206.481 & 6.507 & .000 & .242 \\
Intercept & 17919.677 & 1 & 17919.677 & 564.734 & .000 & .606 \\
Pre-Attitude & .080 & 1 & .080 & .003 & .960 & .000 \\
\hline
\end{tabular}




\begin{tabular}{|l|l|l|l|l|l|l|} 
School location & 28.720 & 1 & 28.720 & .905 & .342 & .002 \\
$\begin{array}{l}\text { Parental Income } \\
\text { School location } \\
\text { Error }\end{array}$ & $* 224.380$ & 2 & 112.190 & 3.536 & $.030^{*}$ & .019 \\
Total & 11645.341 & 367 & 31.731 & & & \\
Corrected Total & 1202785.000 & 386 & & & & \\
\hline
\end{tabular}

a. R Squared $=.242$ (Adjusted R Squared $=.205)^{*}=$ significant at $\mathrm{P}<0.05$

The covariance analysis of students' attitude to environmental education concepts in Table 2 revealed that the two-way interaction effect of family socio-economic status and school location on students' attitude to environmental education is significant $\left(F_{(2,276)}\right.$ $=3.536, \mathrm{P}<.05, \mathrm{\eta} 2=.019)$. The effect size of $1.9 \%$ was negligible. Therefore, the null hypothesis 2 was rejected.

Ho3: There is no significant interaction effect of parental income and school location on students' environmental practices

Table 3: Analysis of Covariance (ANCOVA) of Post-practices by treatment, parental income and school location

\begin{tabular}{|c|c|c|c|c|c|c|}
\hline Source & $\begin{array}{l}\text { Type III Sum of } \\
\text { Squares }\end{array}$ & $d f$ & Mean Square & $\mathrm{F}$ & Sig. & $\begin{array}{l}\text { Partial } \\
\text { Eta } \\
\text { Squared }\end{array}$ \\
\hline Corrected Model & $4033.278^{a}$ & 18 & 224.071 & 5.348 & .000 & .208 \\
\hline Intercept & 31807.863 & 1 & 31807.863 & 759.170 & .000 & .674 \\
\hline Pre-practice & 16.271 & 1 & 16.271 & .388 & .534 & .001 \\
\hline Parental Income & 97.311 & 2 & 48.656 & 1.161 & .314 & .006 \\
\hline School location & 37.896 & 1 & 37.896 & .904 & .342 & .002 \\
\hline $\begin{array}{l}\text { Parental Income * School } \\
\text { location }\end{array}$ & 15.025 & 2 & 7.512 & .179 & .836 & .001 \\
\hline Error & 15376.642 & 367 & 41.898 & & & \\
\hline Total & 1537239.000 & 386 & & & & \\
\hline Corrected Total & 19409.920 & 385 & & & & \\
\hline
\end{tabular}

a. $\mathrm{R}$ Squared $=.208$ (Adjusted R Squared $=.169)$ * $=$ significant at $\mathrm{P}<0.05$

The covariance analysis of students' environmental practices in Table 3 revealed that the interaction effect of family socioeconomic status and school location on students' environmental practices was not significant $\left(F_{(2,276)}=.179, P>.05, \eta 2=.001\right)$. Therefore, the null hypothesis 3 was not rejected. 
In order to disentangle the interaction effect, figure 1 presents the interaction in line graph. The interaction is disordinal.

Fig. 1: Line graph showing interaction effects between family socio-economic status and school location students' attitude to environmental education.

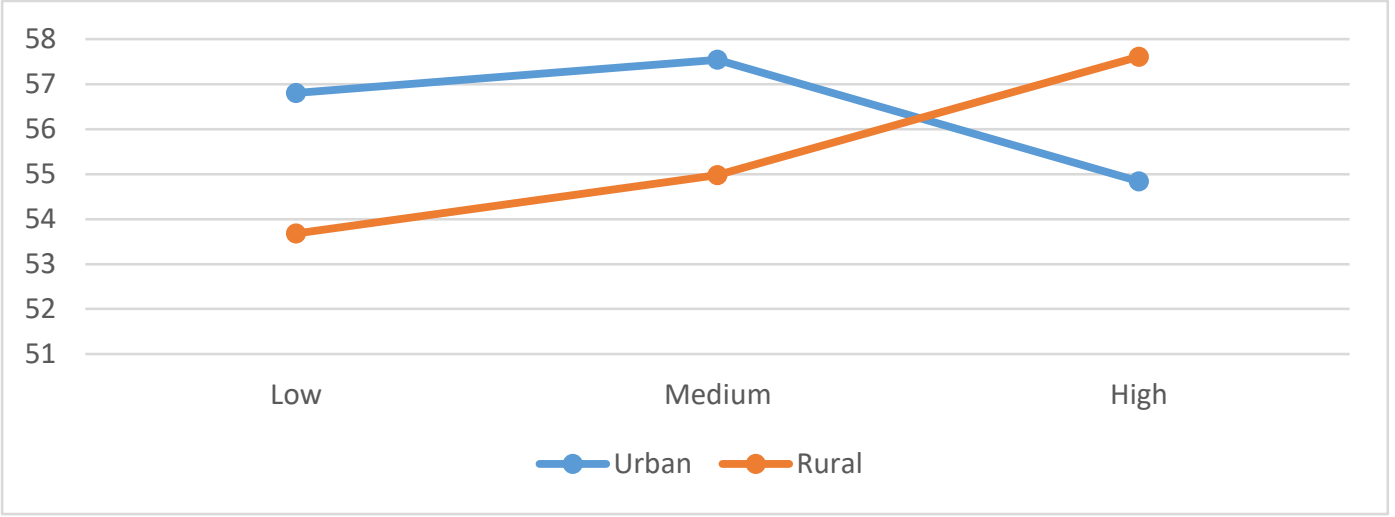

\subsection{Discussion}

\section{Main effect of family socio-economic status on students' knowledge of environmental concepts}

The results of the study revealed that there is no significant main effect of family socio-economic status on students' knowledge of environmental concepts. This may not be connected with the fact that the students were exposed to similar conditions to participate actively in the process of gaining knowledge, this may have accounted for the equal gain in knowledge. The findings of non-significant effect of family socio-economic status was in disagreement with the research works of Balogun (2012) who found that parents who had a high level of education tended to have higher aspirations for their children than less educated parents. Balogun (2012) in his study found that parental educational attainment was significantly related to the educational attainment of their children in both rural and urban areas. Duncan and Magnuson (2005) who concluded that various dimensions of socio-economic status (SES) including household income and cumulative wealth, parents' educational attainment accounts for some portion of these achievement gaps.

\section{Main effect of family socio-economic status on students' attitude to environmental education and environmental practices}

The results of the study revealed that there is no significant main effect of family socio-economic status on students' attitude to environmental education and environmental practices. This implies that the treatment had an equal effect on the students' irrespective of their family socio-economic status level. The findings of the non-significant effect of family socio-economic status was in agreement with the findings of Chevalier and Lanot (2002), who stated, based on the results of their study, that the academic achievement of students with families of poor financial state is continually falling, but that there is no clear result to show that this income has an effect on children's educational outcomes. The findings, however, disagreed with the findings of Heckman $(2008,2011)$ who claimed that children from socio-economically disadvantaged families possess lower levels of cognitive and non-cognitive skills and lag far behind their more advantaged peers. The findings also contradict the research findings of Akanle (2007) who found parental income to be a strong factor upon which the academic and vocational successes of secondary and junior secondary school students lie. The findings also disagreed with the reports of Ushie et al. (2012) that family characteristics are a major source of disparity in students' educational outcomes. 


\section{Main effect of school location on students' knowledge of environmental concepts}

School location was found to have no significant main effect on students' knowledge of environmental concepts in Social Studies. However, urban students had better environmental knowledge than their rural counterparts. Besides, the mean differences were not statistically significant. This may not be connected with the fact that the treatment provided equal learning opportunities for students irrespective of their school location, this may have accounted for the equal gain in knowledge, attitude and practices. The findings are in consonance with the findings of Gbadamosi (2012) who found that school location had no significant effect on pupils' knowledge of environmental concepts. The findings also support the findings of Olatundun (2008) who in his study found that there was no statistically significant effect of school location on learning outcomes. The findings negate the assertion of Ezewu (2009) who asserted that school location generally influences students' perception. The current findings also disagree with Oginni (2008) who suggested that school location could predict school achievement in sciences. Owoeye and Yara (2011) found that students in urban areas had better academic achievement than their rural counterpart.

\section{Main effect of school location on students' attitude to environmental education and environmental practices}

School location was found to have no significant main effect on students' attitude to environmental education and environmental practices. The findings of non-significant effect of school location on students' attitude was in agreement with the findings of Gbadamosi (2012) who found that school location had no significant effect on pupils' attitudes to environmental education. This also corroborates the findings of Adebule and Aborisade (2013) who found that there was no significant difference in the attitude of students from rural and urban setting towards mathematics and that location did not influence the attitude of secondary school students towards mathematics. The findings of non-significant effect of school location on students' environmental practices was in disagreement with the findings of Gbadamosi (2012) in her study found that school location had significant effect on pupils' environmental practices. The findings support the findings of Akintunde (2004) who found that there was no statistically significant effect of school location on learning outcome.

Two-way interaction effects of family socio-economic status and school location on students' knowledge of environmental concepts, attitude and environmental practices

The results revealed that the interaction effects of parental income and school location was not significant on students' knowledge of environmental concepts and practices in Social Studies respectively while the interaction effects of parental income and school location was significant on students' attitude to environmental education concepts in Social Studies. The findings contradict the findings of Akanle (2007) who in his investigation found that parental income cannot be sufficient to sustain the academic and personal social life of the student in sub-rural school areas and this can seriously affect the psychological balance or homeostatic balance in the classroom, which causes low concentration, low perception, frustration, sickness and emotional disability in academic performance of the students and can also lead to drop-out or withdrawal.

\section{Conclusion and Recommendations}

\section{Conclusion}

Therefore, parental socio-economic status has no significant main effect on students' knowledge of environmental concepts, attitude and environmental practices in Social Studies. School location has no significant main effect on students' knowledge of environmental concepts, attitude and environmental practices in Social Studies. There is a significant two-way interaction effect 
of family socio-economic status and school location on students' attitude in Social Studies. However, this interaction effect is not significant on students' knowledge of environmental concepts and practices in Social Studies.

\section{Recommendations}

1. In view of the insecurity in the nation, school security system should be improved upon through vigilance, arial surveillance, information gathering and community collaboration.

2. More public and private security personnel should be deployed regularly to keep the school safe, at all times.

3. Security awareness and sensitization should be done regularly for both staff and students

4. Government should provide more incentives to medium- and low-income earners, especially those in the informal sectors such as artisans, farmers, traders, etc. because the majority of the parents belong to these sectors.

5. Parents should develop more streams of income, as a single income source has become a great economic challenge in Nigeria.

6. Parents are also encouraged to advance more in their academic pursuits because education is an instrument for economic freedom. 


\section{References}

Adebule, S.O. \& Aborisade, O.J. (2013). Influence of study interest and school location on the attitude of secondary school students towards mathematics in Ekiti State, Nigeria. Greener Journal of Educational Research, 3(6), $229-232$.

Ajiboye, J.O. (2010). Social studies education in Nigeria and emerging curricular issues. AOCOED Journal of Social Studies Education in Nigeria. 1(1), 12-18

Akanle, O.B. (2007). Socio-economic factors influencing student's academic performance in Nigeria: Some explanation from a local survey. Free online library on Sociology and Social work community. http://dx.doi.org/10.46827/ejes.v0i0.234

Akintunde, S.A. (2004). Effects of structured and unstructured group interaction patterns on learning outcomes of primary school pupils in some environmental education concepts in Ibadan. Unpublished Ph.D Thesis. Ibadan, Nigeria: University of Ibadan.

Balogun, B.B. (2012). Economics of education in developing countries. Lagos: Iyayi Publishers.

Bandura, A. (2001). Social cognitive theory: An agentic perspective. Annual Review of Psychology, 52, 1-26.

Bussey, K. \& Bandura, A. (1999). Social cognitive theory of gender development and differentiation. Psychological Review, 106(4), 676-713.

Chevalier, A. \& Lanot, G. (2002). The relative effect of family characteristics and financial situation on educational achievement. Education Economics, 10(2), 166-180.

Duncan, G.J. \& Magnuson, K.A. (2005). Can family socioeconomic resources account for racial and ethnic test score gaps? The Future of Children, 15, 35-54.

Ezewu, E. (2012). Sociology of Education. Ibadan: Longman.

Ezewu, E.E. (2009). Social Psychology Factors of Human Learning in School. Onitsha: Leadway Books.

Fontana, C. (2011). Effect of demographic and personal variables on achievement in eighth grade algebra. Journal of Educational Research, 98 (3), 131-135.

Gbadamosi, T. V. (2012). Effects of service learning and educational trips instructional strategies on primary school pupils' environmental literacy in Social Studies in Oyo state, Nigeria. Unpublished Ph.D Thesis. Ibadan, Nigeria: University of Ibadan.

Heckman, J.J. (2008). Schools, skills, and synapses. Economic Inquiry, 46, 289-324.

Heckman, J.J. (2011). The American family in black \& white: A post-racial strategy for improving skills to promote equality. Daedalus, the Journal of the American Academy of Arts \& Sciences, 140, 70-89.

National Center for Education Statistics (2009). High School Longitudinal Study of 2009 (HSLS:09): Second Follow-up Public-Use Data File (NCES 2018-142). Washington, DC: United States Department of Education, Institute of Education Science.

Oginni, A.O. (2008). Social-demographic, school, neighbourhood and parenting influences on academic achievement. Journal of Youth, 34(2), 163-175.

Olatundun, A.O. (2008). Impact of outdoor educational activities on pupils' knowledge and attitude in selected primary Schools in Ibadan, Nigeria. Unpublished Ph.D Thesis. Ibadan, Nigeria: University of Ibadan 
Omoegun, M. (2007). Effect of parental socio-economic status on parental care and social adjustment in the UBE programme," the implication for counseling. International Journal of Educational Research, 3(1), 82-87.

Oni, A.A. (2007). Socio-economic status as predictor of deviant behaviors among secondary school students. International Journal of Educational Research, 3(2), 226-236.

Owoeye, J.S. \& Yara, P. O. (2011). School Location and Academic Achievement of Secondary School in Ekiti State, Nigeria. Asian Social Science, 7(5), $170-175$.

Ugboma, M.U. (2002). Environmental information provision in Nigeria: The case study of oil producing communities. African Journal of Library, Archives \& Information Science, 12(2), 189-199.

Ushie, M.A., Emeka, J.O., Ononga, G.I., \& Owolabi, E.O. (2012). Influence of family structure on students' academic performance in Agege local government area, Lagos state, Nigeria. European Journal of Educational Studies, 4(2), 177 - 187. 